\title{
INDUSTRIALIZACION Y CRECIMIENTO \\ URBANO: LA FORMACION \\ DE LA CIUDAD DE SABADELL *
}

ENRIQUETA CAMPS CURA

European University Institute

\section{INTRODUCCION}

La formación y crecimiento de las ciudades industriales en el siglo $\mathrm{XIX}$ es un fenómeno característico de la transformación capitalista iniciada en algunos países de Europa. La transición al sistema fabril creaba en este período las condiciones que iban a impulsar el rápido desarrollo de las industrias urbanas. La mayor capacidad de expansión de los sectores secundario y terciario de la economía había, a partir de entonces, de alterar las pautas reguladoras del tamaño de las poblaciones, así como la distribución de la actividad entre los distintos sectores productivos. Este es un proceso controvertido que, a largo plazo, sólo podía sustentarse por los aumentos de la productividad agraria que permitiesen alimentar las crecientes proporciones de población integradas en los sectores urbanos. No obstante, desde algunas perspectivas, como la sostenida por el modelo de protoindustrialización, se ha argumentado que en el periodo de formación de las ciudades industriales no fueron tanto excedentes de población agraria los que integraron el crecimiento demográfico urbano, como la movilización del trabajo previamente ocupado en las manufacturas rurales. A partir del grado de detalle que permite el estudio de un ejemplo concreto, se tratará, a continuación, de poner de relieve los orígenes de la transformación industrial en una ciudad catalana, Sabadell, así como las bases de su crecimiento demográfico.

* Para el desarrollo de esta investigación, que constituye parte de mi tesis de grado, debo agradecer la supervisión de J. Maluquer de Motes, las sugerencias de los otros miembros del área de Historia Económica de la UAB, así como la amabilidad de los miem. bros del Archivo Histórico Municipal de Sabadell, que me permitieron consultar el fondo patrimonial de la familia Turull. En todos los casos, la responsabilidad de los posibles errores es sólo mía. 


\section{LA FORMACION DE LA CIUDAD DE SABADELL. EL PROCESO DE INDUSTRIALIZACION}

Aún un municipio manufacturero de poco más de 2.000 habitantes a finales del siglo xvin, la ciudad de Sabadell se formaba a lo largo del siglo posterior merced a los efectos que el proceso de industrialización tuvo sobre su crecimiento demógráfico. Entre 1787 y 1887 se multiplicaba por diez el número de sus habitantes, llegando a los 20.000 en la última fecha. Este era un proceso originado por el crecimiento sostenido de la industria textil, que en 1849 ocupaba el 50 por 100 de la población masculina mayor de quince años y cerca del 70 por 100 de la femenina '. La rápida ampliación de las oportunidades de ocupación en este sector era una consecuencia de la creciente especialización lanera de la ciudad y su comarca, que llegaron a concentrar buena parte de la oferta española de este tipo de textiles. En una fecha tan temprana como el 1861, el Vallés occidental tenía instalados el 66 por 100 de los husos laneros catalanes y el 64 por 100 de los telares, representando el 60 por 100 de la ocupación en este sector ${ }^{2}$. En la misma fecha se puede estimar que la industria de Sabadell y de la ciudad vecina de Tarrasa representaba el 28 por 100 de los husos laneros españoles y el 18 por 100 de los telares, proporciones notables si se tiene en cuenta que un siglo antes alcanzaban porcentajes ínfimos de la pañería de la Península ${ }^{3}$. La transformación de este sector, que conllevaron los procesos de mecanización y transición al sistema fabril, estuvo en el origen de la creciente penetración y predominio de las manufacturas laneras de esta comarca en el mercado español. El éxito de esta transición obedece a distintos tipos de causas que trataré de poner de relieve para el caso de Sabadell.

\section{a) Los factores de localización y dotaciones de recursos energéticos}

Un primer factor relevante para explicar la industrialización de Sabadell es su localización en el prelitoral cercano a Barcelona, principal puerto comercial del Principado. Este hecho sugiere que la ciudad estudiada mantuvo ventajas comparativas para la implantación de la industria en términos de los costes de transporte de las fibras textiles y el carbón importado, y del acceso a las principales redes comerciales. Sabadell, situada en la cuenca del

1 E. Camps Cura (1985), p. 124.

2 Calculado a partir de F. Giménez Guited (1862).

${ }^{3}$ Los porcentajes sobre el total español en 1861 se han calculado teniendo en cuenta los datos señalados por J. M. Benaul Berenguer (1987). A mediados del siglo xviII, el número de telares instalados en ambas ciudades no superaba el centenar, sobre un total de 2.200 telares laneros catalanes y 34.000 telares de lana y lino en el resto de España; véanse J. Torras Elías (1984), R. Aracil y M. García Bonafé (1983). 
río Besós, contaba como único potencial hidráulico con el escaso caudal del afluente Ripoll. A pesar del aprovechamiento intensivo de las aguas de dicho río $^{4}$, el empresariado de la ciudad pronto tuvo que optar por el recurso del carbón para mantener el proceso de mecanización. Las primeras iniciativas se remontan a los años 1838 y 1839 , con la caldera de Magí Planes y el vapor de Josep Formosa, respectivamente. El primer vapor de cierta envergadura, "Cal Pissit», de J. Durán, aparecía en 1842 , seguido, en 1847 , del vapor «Sabadellès», con participación de diversos fabricantes ${ }^{5}$. Durante la década de los años cincuenta el uso del vapor como fuerza motriz se generalizaba. La temprana conexión ferroviaria con Barcelona, en 1855, favoreció este proceso al agilizar el transporte del carbón importado y el comercio de lanas y del producto acabado.

\section{b) La estructura social y el surgimiento de la burguesía industrial}

A finales del siglo xvirI, Sabadell era un municipio artesano especializado en la pañería, actividad que ocupaba una tercera parte de su población ${ }^{6}$. Sobre la base del trabajo doméstico ${ }^{7}$, el municipio se benefició de las posibilidades que ofrecía la ampliación del mercado interior catalán y, de forma más destacada, de la expansión en el período exportador. Entre 1764 y 1787, los niveles de producción de paños de calidades mediana y alta se triplicaron, pasando de las 14.000 a las 45.000 canas anuales ${ }^{8}$. En el contexto de importantes aumentos en la escala de producción, se ampliaba el grado de división social del trabajo y las relaciones corporativas gremiales se erosionaban. Los paraires o fabricantes-comerciantes locales, después de adquirir las lanas en el mercado español, se servían del trabajo campesino en la fase de la hilatura y del trabajo artesanal del municipio en el tisaje ${ }^{9}$, y realizaban el acabado en sus propios talleres. El proceso de diferenciación social, que se agu-

4. M. Benaul Berenguer (1987).

M. Carreras Costajussà (1967).

- Archivo Histórico Municipal de Sabadell, Estadística General de Sabadell, 1797.

${ }^{7}$ F. Zamora, al pasar por Sabadell, señala que «... hay fábricas de paños trabajando cada uno en su casa..... F. Zamora (1973).

- En la primera fecha se contabilizan 27 fabricantes que hacen trabajar 30 telates de continuo y dan trabajo, entre todas las operaciones, a unas 640 personas, entre las cuales se incluyen, sin duda, las mujeres y los niños de las familias campesinas de la comarca. La producción es de 780 fajas de 18 canas de largo, de paños de calidades media y alta; véase Instituto Municipal de Historia de Barcelona, Fondo de la Junta de Comercio, vol. 81, fol. 148. Los datos de 1787 provienen de A. Bosch i Cardellach (1882), p. 55.

'En 1793, «... aunque los operarios que se ocupan en los texidos de paños ordinarios de lana y fabricas de indianas son vecinos de esta villa, sin embargo los cardadores e hiladores de entrambas manufacturas son comunmente de los lugares comarcanos». Archivo Histórico Municipal de Sabadell, «Listado de los frutos y manufacturas de la villa de Sabadell, 1793», Libro de Resoluciones, 1793-1808. 
dizó en estas décadas, había de sentar las bases para la formación de la burguesía y del proletariado de la ciudad.

Posteriormente, al término de las guerras napoleónicas, en 1814, y a la pérdida de las colonias españolas, en 1824, la mayor competencia para la producción textil en el mercado español, así como los nuevos aumentos que se observan en la escala de producción ${ }^{10}$, impulsaron la mecanización de la hilatura, dando lugar a las primeras formas de concentración fabril. Sin duda, la existencia previa del mencionado sector de fabricantes-comerciantes, con cierto bagaje empresarial, formas de control del mercado y también capitales familiares, fue el principal factor que hizo posible esta transición inicial a la industria mecanizada. Un ejemplo característico es el de Pere Turull, hijo de un paraire y pronto uno de los fabricantes más ricos de la ciudad. En 1819, este fabricante instalaba un almacén de lanas para proveer de materias primas la industria de la ciudad ". Durante la primera mitad del siglo xix, Turull articuló una red comercial amplia en el mercado español que iba a garantizar la llegada de sus tejidos a distintos puntos de la Península, así como la adquisición de primeras materias (véase cuadro 1). Esta red, articulada por agentes comerciales a comisión de distintos lugares de España, permitió la penetración en el mercado interior y la llegada de una oferta regular de lanas. La elección de centros estratégicos como Cádiz, además de permitir estar en contacto con la competencia extranjera, había de agilizar el transporte antes del despliegue de la red ferroviaria, al canalizar por vía marítima buena parte del comercio que provenía de la parte sur de la Península.

El mismo sector de fabricantes impulsó la adopción de nueva tecnología, introduciendo el vapor a partir de los años cuarenta y haciéndolo asequible a sectores amplios del empresariado mediante el arrendamiento de la fuerza motriz ${ }^{12}$. La iniciativa de esta burguesía local y la relativa independencia en la financiación de la industria habían de posibilitar el despegue de la actividad lanera en la década de los años cincuenta y el proceso sostenido de acu-

10 Ya en 1828 se puede calcular que la producción lanera habla aumentado en un 50 por 100 respecto de los niveles alcanzados en 1787, llegando a las 3.383 piezas anuales. Esta tendencia se acentúa en los años posteriores, al llegar a doblarse en 1832 los niveles de producción de finales del setecientos. E. Camps Cura (1985), p. 32.

"A. Ribot I Serra, «Nuestros patricios: Pedro Turull», La Ilustración Sabadellense, 1884,1 .

$12 \mathrm{El}$ alquiler de la fuerza motriz fue el medio más usual de fraccionar los elevados costes fijos que suponía el paso al vapor. Las naves industriales con máquina de vapor eran, así, utilizadas por un número variable de fabricantes que, adicionalmente al pago del alquiler del local, pagaban una cuota por el uso de la fuerza motriz. Véase, por ejemplo, Archivo Histórico Municipal de Sabadell, Censo industrial de 1858, en el que se especifican los propietarios de los vapores y los fabricantes que arrendaban el local y la energia. 


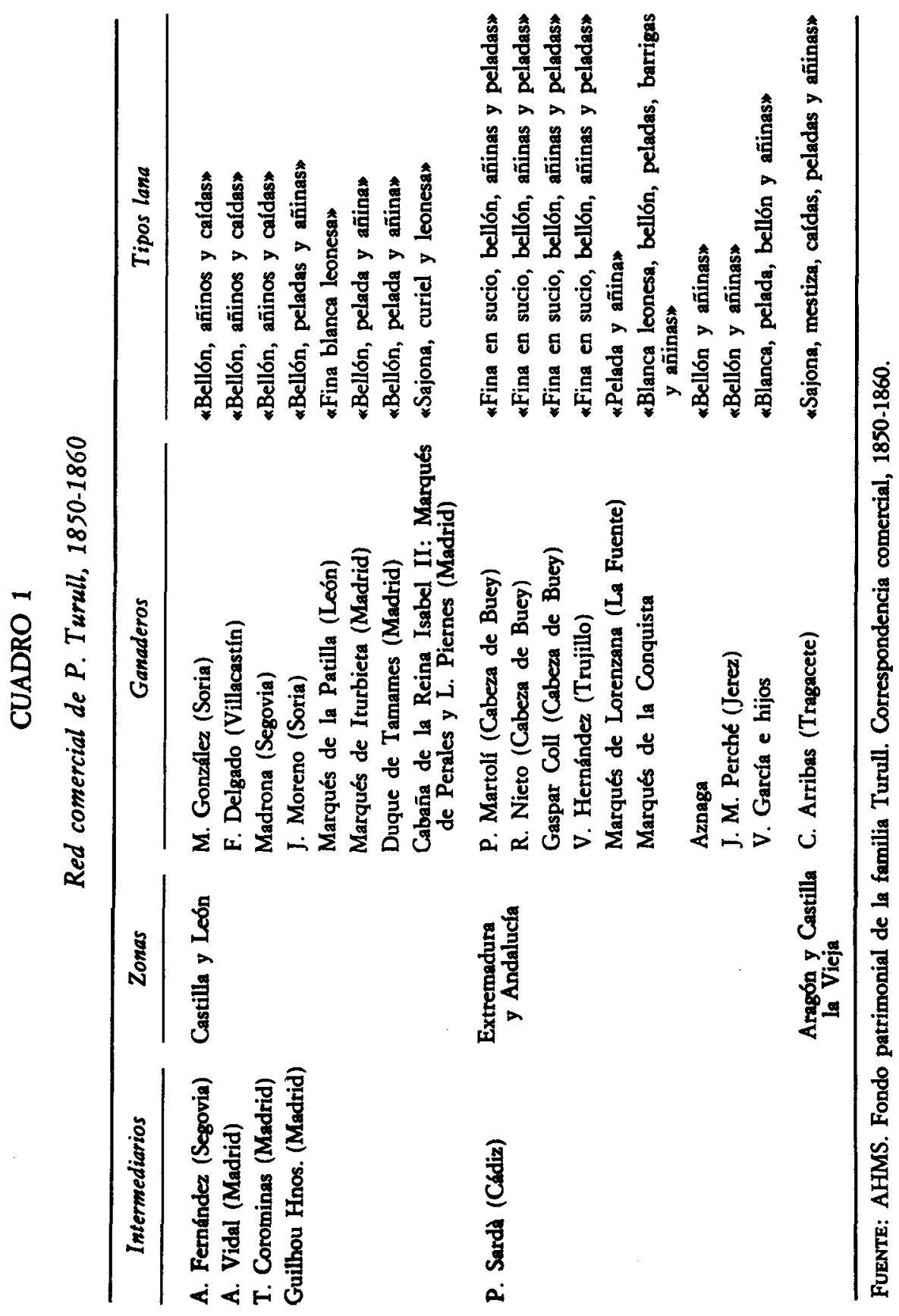


mulación en el propio sector, que llevó a la consolidación de la industria fabril en las décadas posteriores ${ }^{13}$.

\section{c) El proceso de especialización y la estructura de la industria}

Por último, las características del proceso de especialización y la incorporación continuada de innovaciones tienden a explicar los medios por los que la industria de la ciudad mantuvo su competitividad en el mercado español. A lo largo de la primera mitad del siglo xIX, la creciente especialización en paños de calidades media y alta y la introducción de nuevas técnicas, que requerían modestas cantidades de capital fijo, es un proceso renovado en el sector lanero. De entre estas últimas cabe destacar la incorporación del telar jacquard, en 1838, que posibilitó la confección de tejidos de novedad. Este tipo de especialización permitió crear una oferta más diversificada, adaptable a distintos climas y más asequible para los sectores populares de la demanda, merced a los menores requerimientos de trabajo y, por tanto, a las posibilidades de reducir precios ${ }^{14}$. No obstante, la especialización en la confección de estambres no se introdujo hasta el último tercio del siglo ${ }^{15}$. El retraso en este tipo de especialización se puede explicar por la falta de una oferta adecuada de lanas en el mercado español ${ }^{16}$. No fue hasta las últimas décadas del siglo cuando la reducción de los precios internacionales de la lana favoreció su importación desde los centros textiles catalanes. A partir de los años setenta, la importación de lanas largas y peinadas ${ }^{17}$ impulsó la rápida especialización en la confección de tejidos de estambre en una fase ya de total mecanización de la industria.

Paralelamente a la creciente especialización lanera, cabe destacar, a partir de la década de 1850 , la rápida disminución de la implantación del sector algodonero en términos de la ocupación, el número de empresas y el número de telares ${ }^{18}$. De hecho, la penetración de este sector en la ciudad comenzó ya en la última década del siglo xviri, y desde sus inicios obedecía a la iniciativa del capital comercial de Barcelona. A partir de las primeras décadas del siglo xIx, la actividad algodonera de la ciudad se concretaba sobre todo

${ }^{13}$ Distintas investigaciones han puesto de relieve las características del proceso de industrialización en Sabadell. Véanse J. M. Benaul Berenguer (1987), G. Ranzatto (1982), J. E. Linares (1974), E. Camps (1985).

i4 E. Camps (1985), pp. 61-70.

is J. Benaul Berenguer (1981).

16 Grupo de Estudios de Historia Rural (1978).

17 A. Carreras Odriozola (1983a).

18 Coincidiendo con el despegue de la industria lanera, la implantación del sector algodonero disminuye con rapidez. Entre 1850 y 1861 , el número de empresas pasa de 39 a 11; el número de telares, de 1.082 a 472 , y la ocupación, de 1.800 trabajadores a 741 . E. Camps (1985), pp. 40, 46. 
en la utilización del trabajo manual para tejer, organizado sobre la base de empresas de pequeñas dimensiones y manteniendo una relación con el empresario barcelonés similar a la del putting-out-system ${ }^{19}$. Cuando, a partir de la década de los años 1850 , tomó impulso la mecanización de la tejeduría de algodón, esta fase productiva se desplazó de zonas poco dotadas de recursos hidráulicos como Sabadell, y los capitales dirigieron sus inversiones al litoral barcelonés y hacia las cuencas de los principales ríos industriales, que tendieron a concentrar, al igual que en el caso de la hilatura, las mayores proporciones de la maquinaria y del trabajo para tejer ${ }^{20}$.

En realidad se podría concluir que, en buena parte, la crisis de la tejeduría manual algodonera, a partir de mediados de siglo, impulsó la especialización lanera de los fabricantes de la ciudad. Mientras que en el sector algodonero el grado de concentración y las exigencias de mecanización, para las que Sabadell no estaba especialmente bien dotada, pues no tenía ríos con caudal suficiente, constituían barreras para el rápido crecimiento del sector, la lana ofrecía una alternativa mejor para los pequeños fabricantes. Era en el sector lanero, en el que el proceso de concentración estaba menos desarrollado que en el algodonero, donde los fabricantes de la ciudad hallaron oportunidades de mantener su especialización textil e introducir nueva tecnología. El mayor grado de especialización lanera respecto a otros centros catalanes, y también españoles, permitió que la ciudad estudiada mantuviera ventajas comparativas para la producción de tejidos, ampliando sus mercados y llegando a concentrar buena parte de la industria lanera de la Península.

\section{EL CRECIMIENTO DEMOGRAFICO DE LA CIUDAD Y LOS ORIGENES DE LA POBLACION URBANA}

Durante el siglo xIx, Sabadell conoció un espectacular crecimiento demográfico y se formó como ciudad. En todo el período las mayores tasas de crecimiento se alcanzaron entre 1824 y 1857 (véase cuadro 2), coincidiendo con la formación y despegue de la industria mecanizada. Las tasas de crecimiento

19 En las primeras décadas del siglo, la proporción de producción algodonera que se quedaba en la ciudad era del 2,7 por 100 , mientras que la parte restante se vendía a Barcelona para pintar. Véase Archivo Histórico Municipal de Sabadell, Interrogatorio de la Junta de Comercio, 1817. En los años cuarenta, P. Madoz vuelve a hacer notar cómo *... la mayor parte de los tejidos de algodón son dependientes de las grandes fábricas de Barcelona donde se conducen los géneros elaborados diariamente en unos 15616 carros destinados a este objetom. P. Madoz (1842-47). La estructura jerarquizada entre grandes, medianas y pequeñas empresas en el sector algodonero catalán ha sido puesta de relieve por J. Maluquer de Motes Bernet (1976).

${ }^{20}$ Los cambios en la localización de la tejeduría en este período han sido estudiados en E. Camps (1986). 


\section{CUADRO 2}

\section{Crecimiento demogrático de Sabadell}

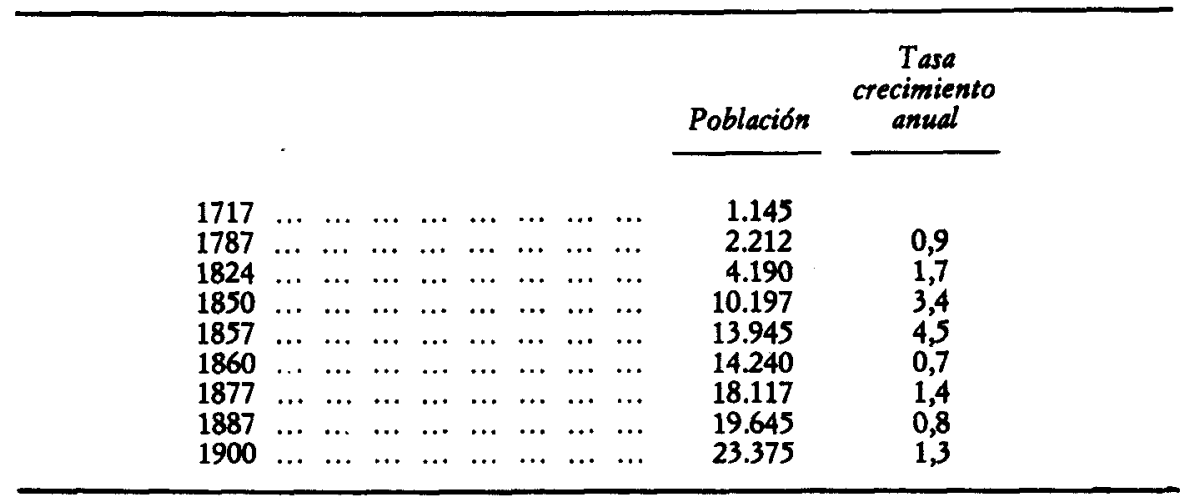

Fuentes: El dato de 1717 proviene del catastro publicado por P. Vilar (1966). Los de $1787,1857,1860,1877$ y 1900 , de los censos de población. Los de 1824 y 1850 , de los padrones municipales de Sabadell.

que se observan ponen de relieve la importancia del proceso migratorio en el crecimiento demográfico de la ciudad. Mientras las tasas de crecimiento natural disminuían progresivamente a causa de una reducción de la fecundidad no compensada por una evolución paralela a la mortalidad ${ }^{21}$, la inmigración pasaba a ser el principal factor impulsor del dinamismo demográfico. Entre 1824 y 1850 las proporciones de población inmigrada crecieron rápidamente, pasando del 22,5 al 36 por 100 de la población total y representando el 47 por 100 de la población entre quince y cincuenta años. En 1889 estas proporciones alcanzaban el 41 por 100 de la población total y el 47 por 100 de la población entre las edades mencionadas ${ }^{2}$. El estudio de la procedencia de la población en el ejemplo de Sabadell pone de relieve los móviles que impulsaron la emigración a la ciudad, así como los orígenes del proletariado urbano. Este tipo de análisis se ha basado en el estudio de tres padrones municipales, que se sitúan en el tiempo en tres momentos característicos: 1824, en la fase de recuperación de la industria posterior a las guerras napoleónicas; 1850, en el período inmediatamente anterior al despegue de la industria mecanizada, y 1889 , en la fase de consolidación del sistema fabril.

${ }^{21}$ E. Camps (1985), p. 152

22 E. Camps (1985), p. 57. 
a) Las características de la inmigración durante la primera mitad del siglo $X I X$

El estudio de los movimientos migratorios pone de relieve las oportunidades cambiantes de ocupación, tanto en las zonas con tendencia a atraer emigrantes como en las áreas con un proceso de expulsión de población. En este sentido, refleja cómo se formó la ventaja comparativa de la industria de la ciudad en relación con la evolución del ingreso y la ocupación en la propia y las restantes comarcas catalanas. Considerando, en términos generales, la emigración como un indicador de niveles de vida inferiores, el grado relativo de bienestar se puede medir en buena parte por la intensidad del flujo migratorio. Para elaborar una estimación de este indicador de intensidad, se ha calculado la proporción que representa la población inmigrada residente en la ciudad respecto de la población de las comarcas y municipios de origen ${ }^{23}$.

Los resultados en términos comarcales (véanse cuadro 3 y mapa 1) muestran cómo entre las zonas de procedencia destaca por su intensidad la emigración desde los municipios de la propia comarca, que llega a alcanzar una proporción del 55 por $1.000,1$ de cada 20 de los residentes, en 1830 , en dicha zona. En los siguientes niveles de intensidad establecidos se sitúan todas las comarcas de la cuenca del Llobregat; la Cerdanya, en la zona de montaña; el Vallès oriental, en la cuenca del Besós, y las partes media y alta de la cuenca del Ter, abarcando toda la zona con anterior implantación de la pañería. No se observa, en cambio, una tendencia a la emigración desde las comarcas agrarias de la parte occidental y el litoral. La emigración procede, sobre todo, de las comarcas industrializadas, sugiriendo las consecuencias que los cambios en la localización de la industria durante la fase de transición al sistema fabril tuvieron sobre los movimientos de la población ocupada en el sector textil.

El detalle de los municipios de procedencia tiende a confirmar los orígenes manufactureros de la emigración a Sabadell. Dentro de la propia comarca, la población inmigrante procede de los municipios industriales y agrarios más próximos. El radio de atracción de la población agraria tiende, de hecho, a circunscribirse a esta zona. Los efectos de la fuerte disminución de los precios agrarios a lo largo de la década de los años veinte ${ }^{24}$, así como la pérdida de las oportunidades de ocupación en la manufactura rural que hasta entonces había completado el ingreso campesino, sugieren las causas de la

${ }^{23}$ Los datos de referencia de la población de las comarcas y municipios de origen durante la primera mitad de siglo son escasos. Para ponderar la proporción que representa la emigración a Sabadell sobre los municipios y comarcas de origen se han utilizado los datos de 1830 publicados por J. Iglesies Fort (1967). Para ponderar los datos de 1889 se ha utilizado el censo de 1887 .

${ }_{24}$ J. Torras Elías (1985), J. Fontana (1985). 


\section{CUADRO 3}

Población según el lugar de nacimiento, 1824

\begin{tabular}{|c|c|c|}
\hline Lugar de nacimiento & Número & 96 \\
\hline $\begin{array}{llllllllll}\text { Sabadell } & \ldots & \ldots & \ldots & \ldots & \ldots & \ldots & \ldots & \ldots & \ldots \\
\text { Vallès occidental } & \ldots & \ldots & \ldots & \ldots & \ldots & \ldots \\
\text { Barcelonès } & \ldots & \ldots & \ldots & \ldots & \ldots & \ldots & \ldots & \ldots \\
\text { Otros } & \ldots & \ldots & \ldots & \ldots & \ldots & \ldots & \ldots & \ldots & \ldots \\
\end{array}$ & $\begin{array}{r}3.444 \\
364 \\
122 \\
263\end{array}$ & $\begin{array}{r}82,1 \\
8,6 \\
2,9 \\
6,4\end{array}$ \\
\hline $\begin{array}{llllllllll}\text { Total } & \ldots & \ldots & \ldots & \ldots & \ldots & \ldots & \ldots & \ldots\end{array}$ & 4.193 & 100 \\
\hline
\end{tabular}

FUENTE: Elaboración propia a partir del padrón municipal de 1824.

\section{MAPA 1}

Intensidad de la emigración a Sabadell en términos comarcales, 1850

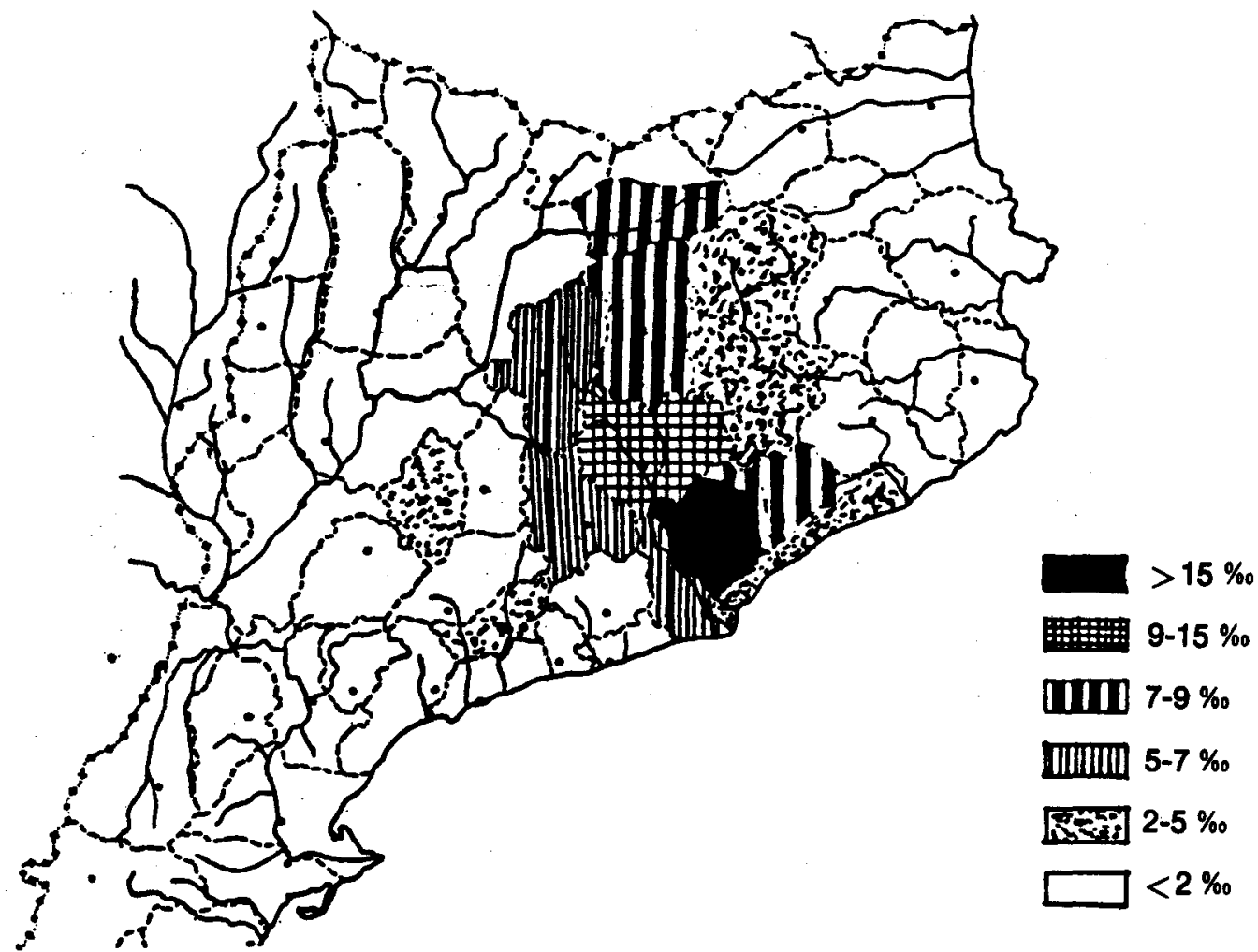




\section{CUADRO 4}

Población según el lugar de nacimiento, 1850

\begin{tabular}{|c|c|c|c|c|}
\hline Lugar de nacimiento & Número & $\%$ & $\begin{array}{c}(2) \\
\text { Población } \\
\text { comarcal } \\
1830\end{array}$ & $\begin{array}{c}(3) \\
(1) /(2) \\
\text { por } \\
\text { mil }\end{array}$ \\
\hline 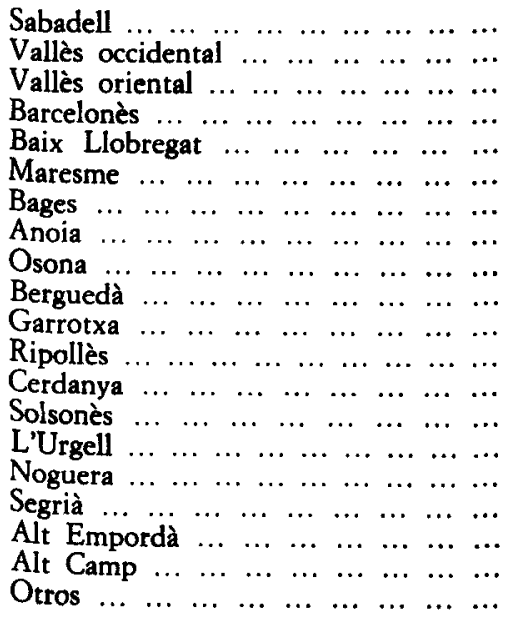 & $\begin{array}{r}6.359 \\
1.400 \\
260 \\
384 \\
133 \\
108 \\
397 \\
175 \\
96 \\
104 \\
54 \\
50 \\
108 \\
32 \\
45 \\
9 \\
5 \\
15 \\
50 \\
418\end{array}$ & $\begin{array}{l}62 \\
14 \\
3 \\
3,8 \\
1,3 \\
1,05 \\
3,8 \\
1,7 \\
0,94 \\
1,01 \\
0,52 \\
0,48 \\
1,05 \\
0,31 \\
0,44 \\
0,08 \\
0,04 \\
0,14 \\
0,48 \\
4,09\end{array}$ & $\begin{array}{r}25.087 \\
29.310 \\
114.292 \\
21.345 \\
53.076 \\
38.630 \\
28.428 \\
44.072 \\
13.970 \\
29.689 \\
17.310 \\
13.267 \\
6.237 \\
17.702 \\
31.795 \\
23.548 \\
56.448 \\
21.989\end{array}$ & $\begin{array}{r}55,8 \\
8,87 \\
3,35 \\
6,23 \\
2,03 \\
10,27 \\
6,15 \\
2,17 \\
7,44 \\
1,81 \\
2,87 \\
8,14 \\
5,13 \\
2,54 \\
0,28 \\
0,21 \\
0,26 \\
2,59\end{array}$ \\
\hline 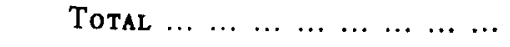 & 10.209 & & & \\
\hline
\end{tabular}

FUENTE: Elaboración a partir del padrón municipal de 1850.

emigración del campesinado a la ciudad, que se inicia en el mencionado período.

Fuera de la comarca, entre los municipios de origen de la población emigrante, destacan centros con una importante tradición en la pañería, como Moià, Castelltersol, Olesa, Monistrol, Capellades, entre otros, además de centros laneros de montaña, como Berga y Puigcerdà. A lo largo del siglo xviII, en todas estas áreas aumentaba el grado de dedicación a la pañería merced a los efectos que el desarrollo de una agricultura de exportación altamente lucrativa en otras zonas catalanas, y la creciente especialización territorial en las distintas actividades productivas, tuvieron de elevar la renta disponible para el consumo de manufacturas en el mercado interior ${ }^{25}$. En la zona

\footnotetext{
${ }^{25}$ P. Vilar (1966), J. Torras Elías (1984), J. Maluquer de Motes Bernet (1985).
} 


\section{MAPA 2}

Intensidad de la emigración a Sabadell según el municipio de origen, 1850

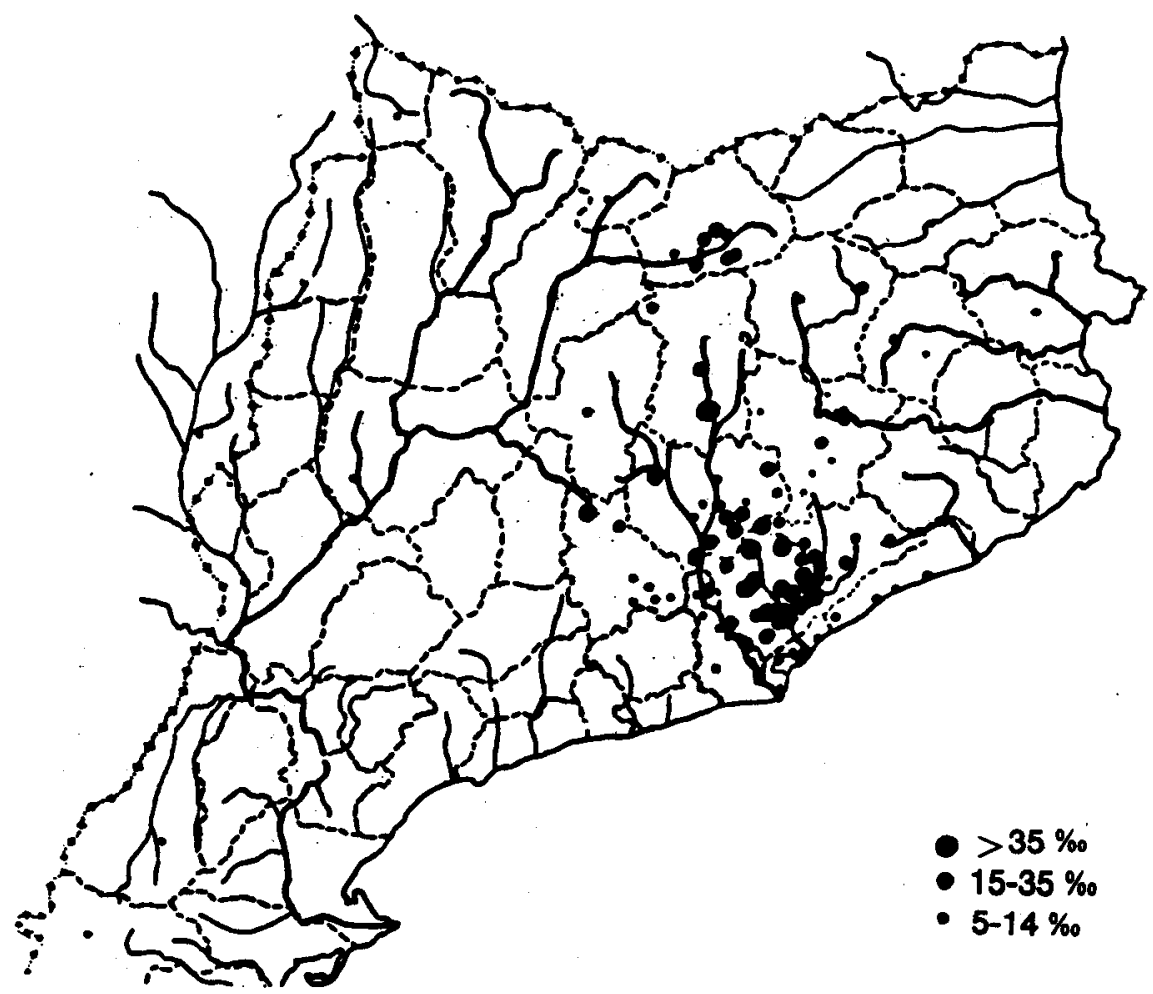

Fuente: Padrón municipal de Sabadell 1850.

de la depresión central se acentuaba la especialización en la producción de paños destinados al consumo popular, ampliándose el grado de división social del trabajo ${ }^{26}$. La producción textil llegaba a ramificarse por auténticas constelaciones de hogares campesinos que realizaban la hilatura y las operaciones preliminares ${ }^{27}$.

20 J. Torras Elías (1984).

n Por ejemplo, en Moià, a finales del siglo xviII, «... se emplea mas de 300 familias a mas de siete lugares circunvecinos unos dentro y otros fuera del Moianés..... Véase $\mathrm{Pa}$ lacio Real de Madrid, F. Zamora, Respuesta al interrogatorio de Moià. En ciudades como Manresa o Igualada, la hilatura se llevaba a cabo por las mujeres de las familias campe- 
Durante las primeras décadas del siglo xIx, el impacto inicial de la crisis agraria había de repercutir en gran medida sobre estas áreas laneras dependientes de la evolución del consumo popular. A pesar del carácter transitorio de la crisis agraria, cabe tener en cuenta sus efectos encadenados sobre el empobrecimiento y descapitalización del artesanado, con una producción destinada a los sectores populares de la demanda. También son considerables sus consecuencias sobre el proceso de concentración, al hacer necesaria la tenovación tecnológica para subsistir en un contexto económico recesivo. El proceso de mecanización mismo imponía cambios sensibles en la localización de la industria al hacer necesaria la disponibilidad de recursos hidráulicos o la proximidad a los puertos de llegada del carbón importado. En la década de 1850 la actividad manufacturera había ya casi desaparecido en la zona de montaña. En los municipios de las comarcas industrializadas interiores, alejados de los cauces de los ríos, la actividad textil quedó reducida al tejido manual algodonero, que se dispersaba por las zonas rurales merced a los efectos multiplicadores que la mecanización de la hilatura tuvo sobre la demanda de trabajo manual para tejer ${ }^{28}$. No obstante, este tipo de especialización no podía ya compensar los efectos de la recesión de la pañería en aquellas zonas donde anteriormente este tipo de actividad había mantenido ocupados a elevados contingentes de población.

Las características de una emigración mayoritariamente textil pueden verificarse de nuevo al comprobar las profesiones en las que se integró la población llegada a la ciudad (véase cuadro 5). Los inmigrantes se ocupaban sobre todo en los trabajos cualificados del textil, y, en los casos de la población que provenía del Vallés, el Bages y el Barcelonés, se observa también la llegada de los comerciantes-fabricantes que habían articulado el proceso productivo. La inmigración de trabajadores de origen agrícola es minoritaria desde todas las comarcas, exceptuando el Vallés occidental y el oriental, donde se pone de relieve la llegada de la población de los municipios agrarios en recesión vinculados parcialmente a la producción manufacturera. De otro lado, la recesión de la actividad textil en el resto de las comarcas mencionadas tuvo efectos encadenados sobre las otras ocupaciones urbanas, como los artesanos de la madera y del metal, los trabajadores de la construcción, transporte y comercio, que dependian estrechamente de la actividad industrial.

Tal como se ha puesto de relieve, las características de la emigración a Sabadell se pueden considerar como un contraejemplo que permite matizar la difundida idea de que la transición a la industria fabril urbana fue un proceso que había de generar importantes movimientos migratorios de la pobla-

sinas a un radio de distancia de tres a cuatro horas de ambas ciudades, respectivamente. Véanse V. Ferrer Alós (1985), J. M. Torras i Ribé (1974).

E. Camps (1986). 


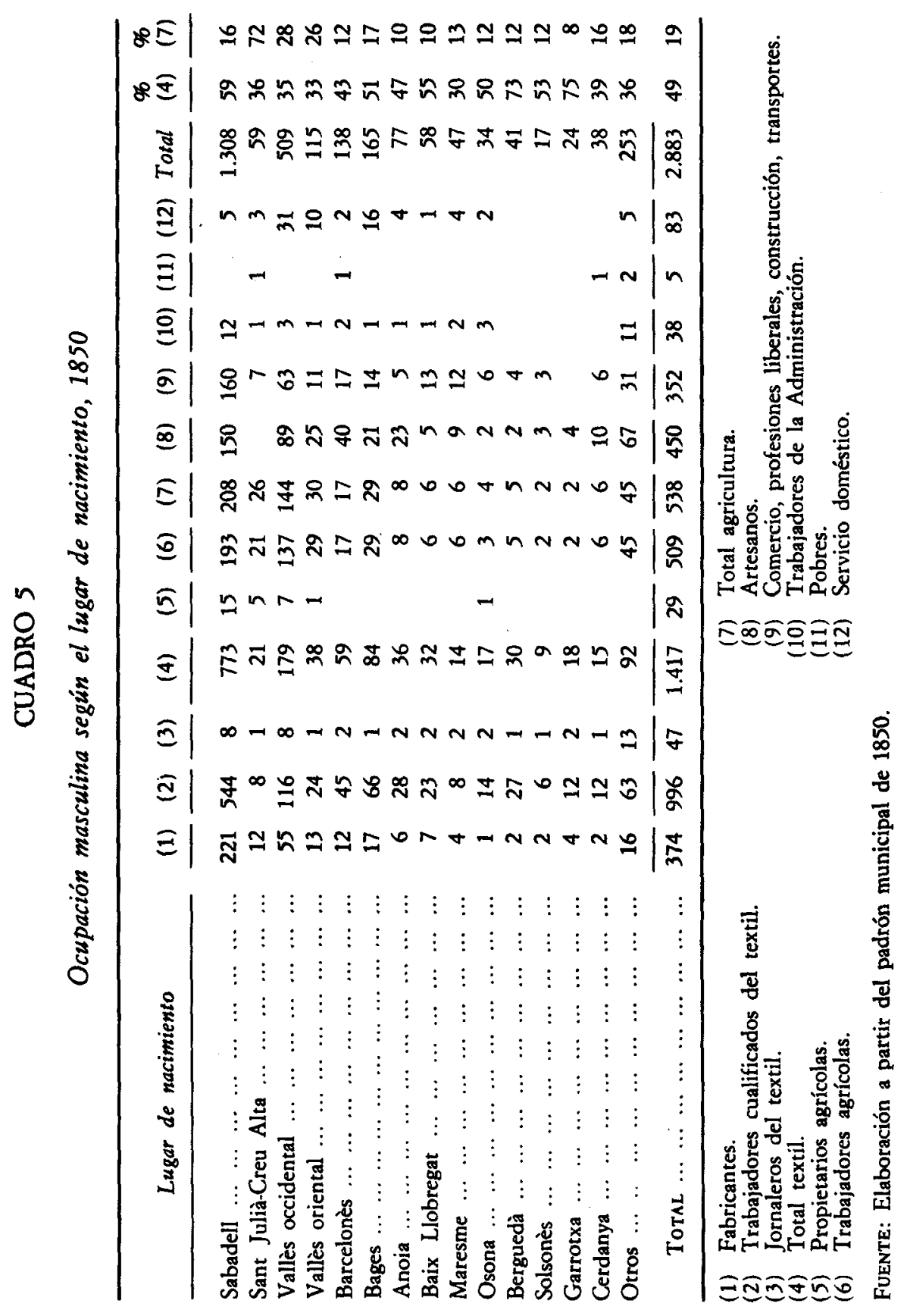


ción agraria a la ciudad industrial ${ }^{29}$. Probablemente en este período, desde la perspectiva de la población rural, no hubo cambios importantes en la intensidad de la emigración, teniendo en cuenta que ya en el siglo xviII la población era muy móvil ${ }^{30}$. Los cambios más notables se observan en el destino de la emigración de la población antes ocupada en la manufactura rural. La crisis de la pañería tradicional y la pérdida de las oportunidades de ocupación en este sector fueron el principal factor que impulsó la emigración a la ciudad industrial.

A pesar de las diferencias entre el modelo de protoindustrialización y las pautas de crecimiento de la economía catalana en el siglo xviII ${ }^{31}$, cabe, no obstante, destacar que las características de los movimientos migratorios en el ejemplo estudiado tienden a confirmar las hipótesis sostenidas en el primer modelo a este respecto ${ }^{32}$. La expansión de las manufacturas rurales en el siglo xviII generó los excedentes de población, que posteriormente se integraron en la ciudad industrial. La existencia de un desarrollo industrial previo tiende, pues, a explicar los orígenes de la población que se integró en la industria de fábrica, así como la capacitación técnica sobre la que se sostuvieron las progresivas transformaciones del sistema productivo.

\section{b) Las migraciones durante la segunda mitad del siglo XIX}

En el contexto catalán, el despoblamiento de las zonas rurales agrarias, a partir de la década de 1860 , era una tendencia simultánea al retroceso en las tasas de crecimiento de las ciudades de tamaño medio formadas en la primera mitad de siglo ${ }^{33}$. La creación de excedentes de población agraria era, así, un proceso paralelo a la formación de excedentes de trabajo en el propio sector industrial. Algunas ciudades y zonas industriales perdían población, a causa de la dinámica del proceso de mecanización y también de las alternancias que éste generó en la localización de la industria ${ }^{34}$.

A pesar de la tendencia señalada al retroceso demográfico de las zonas rurales agrarias, puede observarse cómo las zonas de origen de la población inmigrada de Sabadell en 1889 son, al igual que en la primera mitad de siglo, áreas industriales. Los mapas 3 y 4 y el cuadro 6 ponen de relieve cómo la procedencia de la inmigración se extiende con mayor intensidad por los mu-

${ }^{29} \mathrm{~W}$. Zelinsky (1971).

30 P. Vilar (1966).

"En el caso catalán, el papel del cambio agrario, del mercado interior y del capital comercial en el crecimiento y desarrollo de las manufacturas rurales ponen en duda la aplicabilidad de dicho modelo. Véanse P. Vilar (1966), J. Nadal (1975), J. Torras (1984).

${ }^{32}$ F. F. Mendels (1972), J. de Vries (1984).

${ }^{33}$ E. Camps (1986).

${ }^{34}$ J. Nadal (1975), A. Carreras (1983 b). 


\section{MAPA 3}

Intensidad de la emigración a Sabadell en términos comarcales, 1889

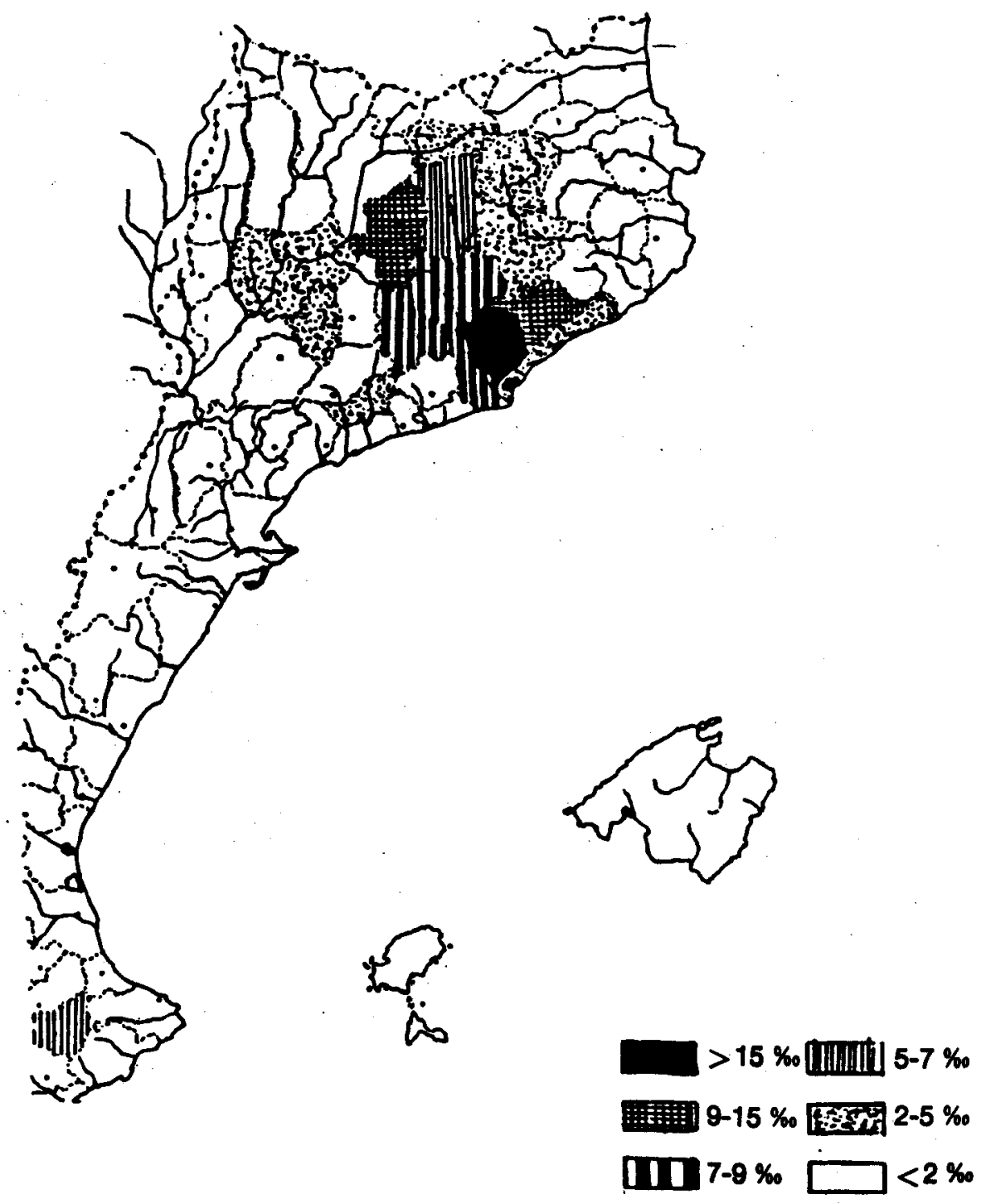

Fuente: Padrón municipal de Sabadell de 1889. 


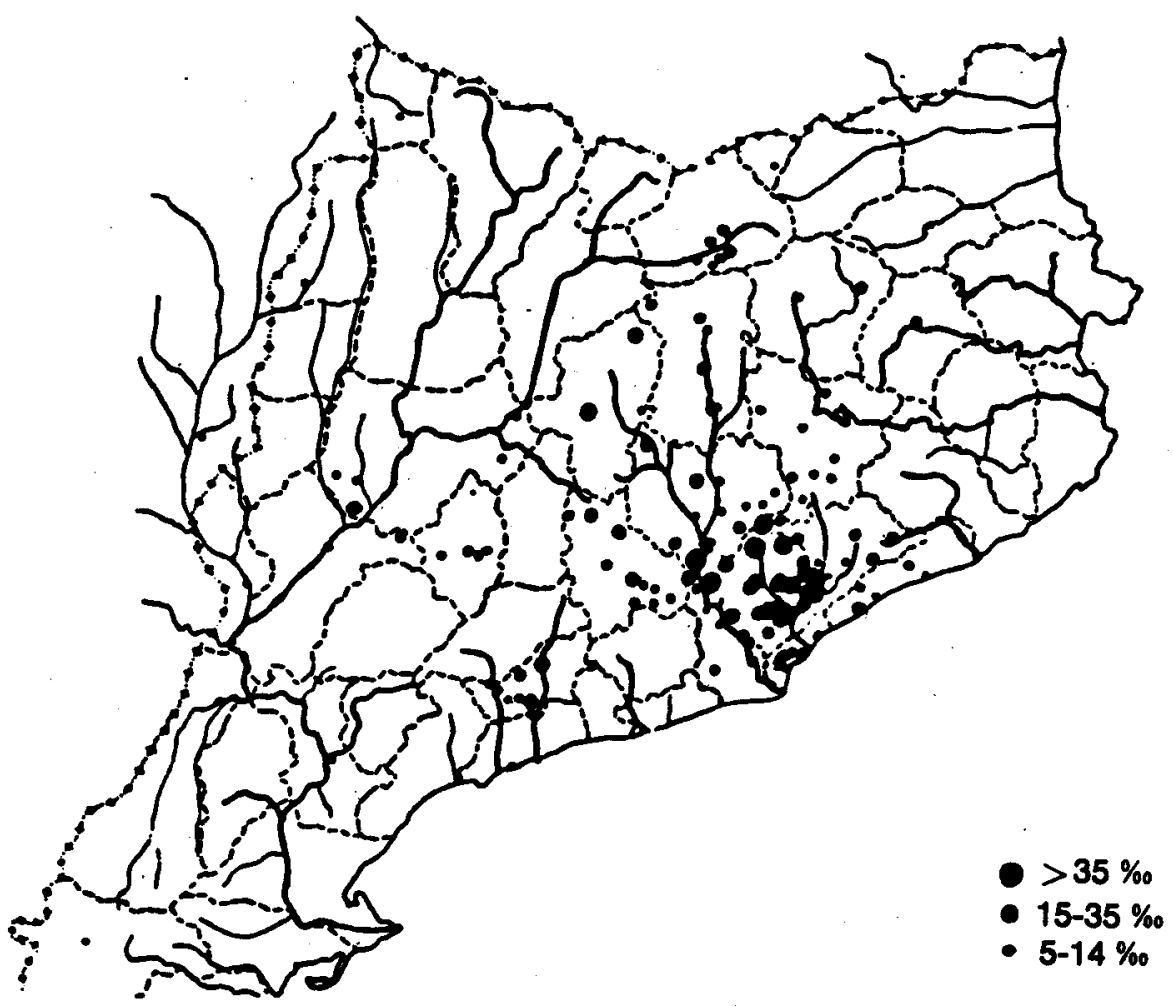

Fugnte: Padrón municipal de Sabadell de 1889.

nicipios de la propia comarca, ampliándose el radio de influencia por los pueblos de las comarcas industrializadas limítrofes en las cuencas del Besós y el Llobregat. Con menores intensidades, la inmigración procede también de las zonas algodoneras de el Berguedà, l'Osona y la Garrotxa, cubriendo toda la cuenca del Llobregat y las partes media y alta del Ter. Adicionalmente se observa también una emigración de poca intensidad desde la zona del litoral barcelonés y el Maresme. Fuera del Principado, los movimientos migratorios a Sabadell alcanzan una intensidad notable desde la comarca lanera de Alcoy.

Dentro de la propia comarca, cabe destacar el impacto del proceso de me- 


\section{CUADRO 6}

Lugar de nacimiento de la población, 1889

(1)

\begin{tabular}{|c|c|c|c|c|}
\hline Lugar de nacimiento & Número & $\%$ & $\begin{array}{c}\text { Población } \\
\text { comarcal } \\
1887\end{array}$ & $\begin{array}{c}(1) /(2) \\
\text { por } \\
\text { mil }\end{array}$ \\
\hline 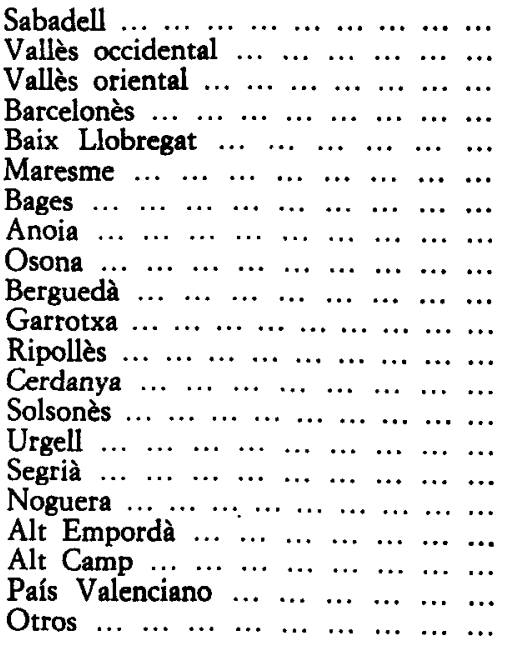 & $\begin{array}{r}11.329 \\
2.550 \\
413 \\
784 \\
379 \\
202 \\
556 \\
307 \\
195 \\
124 \\
75 \\
66 \\
61 \\
139 \\
119 \\
78 \\
100 \\
81 \\
177 \\
654 \\
1.331\end{array}$ & $\begin{array}{l}57,4 \\
12,9 \\
2,09 \\
3,6 \\
1,9 \\
1,02 \\
2,8 \\
1,5 \\
0,9 \\
0,6 \\
0,3 \\
0,3 \\
0,3 \\
0,7 \\
0,6 \\
0,3 \\
0,5 \\
0,4 \\
0,8 \\
3,3 \\
6,7\end{array}$ & $\begin{array}{r}66.397 \\
41.882 \\
432.084 \\
44.067 \\
69.845 \\
67.795 \\
40.332 \\
55.856 \\
22.406 \\
39.938 \\
24.791 \\
12.724 \\
12.259 \\
32.775 \\
62.691 \\
44.772 \\
71.990 \\
38.695\end{array}$ & $\begin{array}{r}35,5 \\
9,8 \\
1,8 \\
8,6 \\
2,9 \\
8,2 \\
7,6 \\
3,4 \\
5,5 \\
1,8 \\
2,6 \\
4,7 \\
11,3 \\
3,6 \\
1,3 \\
2,2 \\
1,1 \\
4,5\end{array}$ \\
\hline Total $\ldots \ldots \ldots \ldots \ldots$ & 19.720 & & & \\
\hline
\end{tabular}

FUENTE: Elaboración a partir del padrón municipal de 1889.

canización y la adopción del vapor sobre la recesión de las pequeñas empresas de trabajo manual y algunas hilaturas vigentes hasta la década de los años 1850 . Los efectos del proceso de mecanización habían de ser paralelos a los que el despliegue de la red ferroviaria tuvo sobre la crisis de los mercados locales y comarcales, en los que se había basado en parte el pequeño campesinado. Los municipios de origen de la inmigración son agrarios, y también manufactureros, sugiriendo el influjo de ambos tipos de causa sobre la emigración a la ciudad.

En el resto de las comarcas industrializadas los municipios de origen sugieren distintos tipos de factores explicativos de los desplazamientos de la población. Las pequeñas empresas de tejido manual algodonero que se habían extendido por algunas áreas poco dotadas de recursos hidráulicos -Vallés oriental, pueblos de la parte sur de la comarca de Osona y la parte sureste 
del Bages, el Solsonés- desembocaron en una crisis irreversible a partir de las décadas 1850-60 en que se acelera la mecanización de la tejeduría. Dichas zonas entraron en una fase de desindustrialización definitiva por la falta de los recursos naturales necesarios para impulsar la mecanización ${ }^{35}$.

Con mayor intensidad, los cambios en la localización de la industria afectaron la comarca del Anoia y su capital, Igualada. En 1850, Igualada era la segunda ciudad del Principado por la importancia de su industria algodonera, inmediatamente después de Barcelona. No obstante, la falta de recursos hidráulicos, y también la ausencia de conexiones ferroviarias con el litoral, impulsaron la profunda recesión industrial de esta ciudad y su comarca a partir de la década de $1850^{36}$. De forma parecida, los pueblos del interior del Baix Llobregat -Olesa, Esparraguera - acusaron los efectos del proceso de mecanización sobre la dirección de los capitales hacia el litoral o hacia las zonas media y alta del Ter y el Llobregat.

Sin embargo, se pueden también observar las características de una emigración distinta que procede de las ciudades industriales donde tomó impulso el proceso de mecanización -Barcelona, Mataró, Manresa o Sallent-. En estos casos, la cronología de la llegada a la ciudad ${ }^{37}$ sugiere los efectos de las crisis puntuales en el sector algodonero (crisis de demanda por malas cosechas en 1856-57; crisis de la fam del cotó en los años sesenta, seguida de la crisis financiera del 1866 y la crisis de demanda de los años ochenta) sobre el cierre simultáneo de empresas, que había de impulsar la emigración forzosa.

En las comarcas de la Garrotxa y el Berguedà las características de la emigración son también diversas. Tienden a concentrarse en el tiempo en las décadas de los años 1850-60, para disminuir sensiblemente durante los años setenta y volver a aumentar a partir de la crisis de los años ochenta. Los efectos sobre la emigración del desplazamiento de la industria hacia la zona litoral y central, hasta los años sesenta, cesaron de operar en los años setenta en que la conexión ferroviaria con el litoral y la adopción de la turbina volvieron a atraer capitales hacia las zonas de montaña ${ }^{38}$. No obstante, la crisis agraria de los años ochenta, crisis de demanda para el sector textil, parece de nuevo tener influencia sobre la emigración desde esta zona.

Por último, se ha puesto también de relieve la emigración desde la comarca de Alcoy, en el País Valenciano, que llega a representar el 8 por 1.000 de la población registrada en 1877 . La emigración de la población valenciana

${ }^{35}$ Los cambios en la localización de la industria en la comarca de Osona han sido reflejados en J. Albareda Salvadó (1981). El proceso de crisis de la tejeduría manual y los cambios en la localización de los telares que originó han sido estudiados en E. Camps (1986).

36. J. Nadal (1975), J. M. Torras i Ribé (1974).

37 E. Camps (1985), pp. 240-241.

3 A. Carreras $(1983 \mathrm{~b})$. 


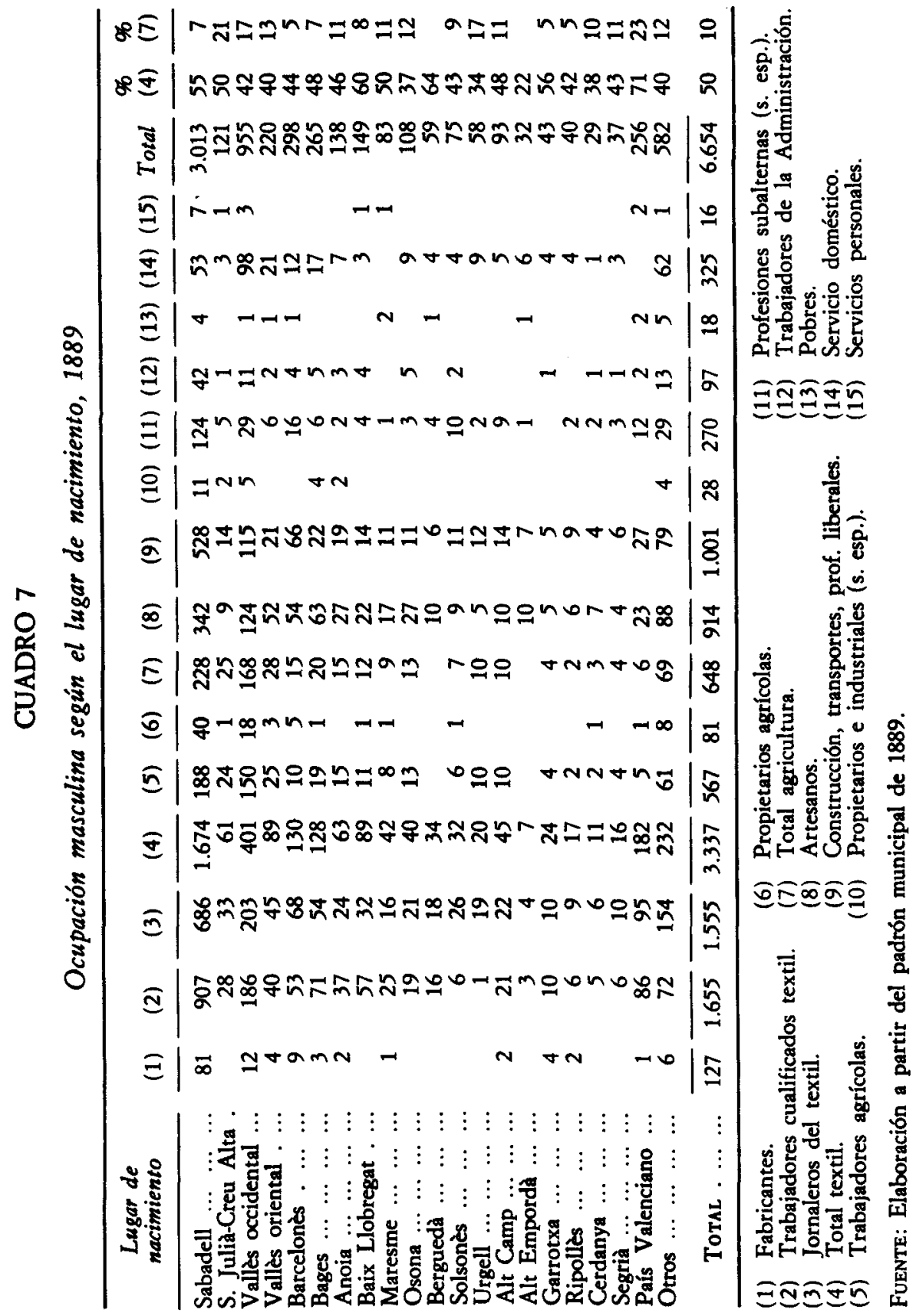


a Sabadell coincide, de hecho, con un período de recesión de la industria lanera y el estancamiento demográfico de la región de Alcoy entre 1877 y $1887^{39}$. A diferencia de la industria lanera del Vallés, que en los años setenta conocía la especialización en estambres y la mecanización de la tejeduría, los telares mecánicos no se introdujeron en Alcoy hasta 1885. Este hecho sugiere que en este período los tejidos alcoyanos perdieron competitividad en el mercado español, generando el retroceso y desocupación en el sector lanero.

$\mathrm{La}$ competencia industrial, los efectos de las crisis puntuales en el sector algodonero y, sobre todo, la falta de recursos naturales para impulsar el proceso de mecanización sugieren las principales causas que originaron la emigración de la población industrial a Sabadell. Las ocupaciones de la población llegada a la ciudad (véase cuadro 7) permiten de nuevo verificar las bases industriales de la emigración que contribuyó al rápido crecimiento demográfico urbano.

\section{CONCLUSIONES}

La formación de la ciudad de Sabadell es un ejemplo claro que permite poner de relieve los efectos que el proceso de concentración industrial catalán del siglo xIX tuvo sobre el crecimiento urbano. Refleja también con nitidez cómo el desarrollo de la manufactura a lo largo del siglo xvirI sentó las bases para la formación de la burguesía y el proletariado de la ciudad. La existencia previa de un sector del artesanado, con bagaje empresarial y formas de control del mercado, sugiere cuál fue la procedencia de la burguesía que impulsó la transición a la industria mecanizada. Aprovechando la situación favorable de la ciudad en el prelitoral cercano a Barcelona, la iniciativa comercial de este incipiente empresariado, el impulso al proceso de renovación tecnológica, así como el mayor grado de especialización lanera alcanzado respecto de otros centros catalanes y españoles, permitieron que Sabadell mantuviese ventajas comparativas para la producción textil, ampliando sus mercados y llegando a concentrar buena parte de la industria lanera española.

En segundo lugar, los orígenes de la inmigración, que contribuyó al rápido crecimiento demográfico de Sabadell, ponen de relieve cómo el desarrollo previo de las manufacturas rurales creó los excedentes demográficos a partir de los cuales se formaba el proletariado de la ciudad. Durante la primera mitad de siglo, los municipios de origen de la población inmigrada se circunscriben a toda la zona con anterior implantación de la pañería. La crisis de la manufactura textil doméstica en algunas zonas, que siguió a la transición

\footnotetext{
39 R. Aracil y M. García Bonafé (1974).
} 
a la industria mecanizada en otras, muestra cuáles fueron las principales causas que impulsaron la emigración a la ciudad. Este hecho viene a modificar la extendida idea de que el crecimiento demográfico de las ciudades industriales fue un proceso que habia de requerir de importantes trasvases de población del sector agrario a los sectores urbanos. En el contexto de un importante crecimiento de la población en las zonas rurales agrarias, la recesión, y en muchos casos desindustrialización de las zonas donde se había extendido la pañería doméstica, generó los movimientos migratorios hacia la ciudad industrial, donde la ocupación textil se ampliaba sobre la base de las primeras formas de concentración fabril.

En la segunda mitad de siglo, a pesar de los importantes excedentes de población generados en el sector agrario, la procedencia de la inmigración siguió siendo sobre todo industrial. En este período, las características de la emigración a la ciudad ponen de relieve una gran movilidad del proletariado textil, como consecuencia de las crisis puntuales en el sector algodonero y de los cambios en la localización de la industria que el mismo proceso de mecanización impulsó. No obstante, el hecho de que Sabadell no fuera receptora de la emigración generada en el sector agrario sugiere que la cualificación y aprendizaje previos condicionaron el acceso a las ocupaciones textiles de la ciudad industrial. Sin duda, el conocimiento de las técnicas de producción permitía a los trabajadores textiles inmigrantes mantener una posición ventajosa en el mercado de trabajo respecto de los trabajadores de procedencia agraria. Alternativamente, la emigración de origen agrario había de dirigirse a una ciudad como Barcelona, con mayor desarrollo de los servicios urbanos y ocupaciones poco cualificadas.

\section{REFERENCIAS}

Albareda Salvadó, Joaquim (1981): La industrialització a la Plana de Vic, Vic, Ed. Eumo. Aracil, Rafael, y Garcí Bonafé, Marius (1974): La industrialització al Pais Valencià, Valencia, Ed. Eliseu Climent.

- (1983): "La protoindustrialització i la industria rural espanyola al segle xviII», Recerques, 13.

Benaul, Josep M. (1987): La industria llanera catalana 1814-1914 (en curso de publicación).

Bosc h i Cardellach, Antoni (1882): Memories de Sabadell 1792, Sabadell.

CAMPS CuRA, Enriqueta (1985): La formació d'una ciutat catalana sota l'impuls de la industrialització, Sabadell 1770-1890 (tesis de licenciatura), UAB.

- (1986): La formación de ciudades en la transición al capitalismo industrial: Cataluña siglos XVIII y XIX, Florencia, Instituto Universitario Europeo (inédito).

Carreras Costajussa, Miquel (1967): Elements d'bistoria de Sabadell, Sabadell, A. Castells Artgrafia. 
Carreras Odriozola, Albert (1983 a): La producció industrial espanyola $i$ italiana desde mitjans del segle $X I X$ fins a l'actualitat (tesis doctoral), UAB.

- (1983 b): «El aprovechamiento de la energía hidráulica en Cataluña 1840-1920. Una aproximación a su estudiom, REvista de Historia ECONÓmICA, 2.

DE VRIES, Jan (1984): European Urbanization 1500-1800, Londres, Methuen and Co. Ltd.

Ferrer Alós, Llorens (1985): «Los orígenes de la industrialización en Cataluña. La ciudad de Manresan, III Congreso de Historia Económica, Segovia.

Fontana, Josep (1980): "Crisi camperola i revolta carlina», Recerques, 10.

- (1985): «La crisis agraria de comienzos del siglo xIX y sus repercusiones en España», en García Sanz, A., y Garrabou, R.: Historia agraria de la España contemporánea. Cambio social y nuevas formas de propiedad, Barcelona, Crítica.

GiméNEZ GuITED, Francisco (1862): Gúáa fabril e industria de España, Madrid.

Grupo DE Estudios dE Historia RuRal (1978): "Contribución al análisis de la ganadería española, 1865-1929n, Agricultura y Sociedad, 8.

IglESIES FoRT, Josep (1967): "Indagaciones sobre la población de Cataluña en la primera mitad del siglo XIX», Memorias de la Real Academia de Ciencias y Artes de Barcelona, vol. 37, Barcelona.

Linares, Juan E. (1974): Plataforma socioeconómica de la industrialización de Sabadell (tesis de licenciatura), UAB.

Madoz, Pascual (1842-47): Diccionario Geográfico, Histórico y Estadístico de España y sus posesiones en Ultramar, Madrid.

MALUQUER DE MOTES, Jordi (1976): «La estructura del sector algodonero en Cataluña durante la primera etapa de la industrialización», Hacienda Pública Española.

- (1985): «La revolución industrial en Cataluña», en SÁNCH Ez-AlBornoz, N.: La modernización económica en España, 1830-1930, Madrid, Alianza.

Mendels, Franklin F. (1972): „Proto-industrialization. The First Phase of the Industrialization Process», Journal of Economic History, 32, 1.

NaDAL, Jordi (1975): El fracaso de la revolución industrial en España, Barcelona, Ariel.

RANZATTO, Gabriel (1982): «Industrializzazioni spontanea e liberal democrazia: il caso della Manchester catalana», Rivista di Storia Contemporanea, 3.

ToRras Elías, Jaume (1984): «Especialización agrícola $e$ industria rural en Cataluña en el siglo xviIm, Revista de Historia ECONÓmICA, 3.

- (1985): «Aguardiente y crisis rural. Sobre la coyuntura vitícola, 1793-1832», en García Sanz, A., y Garrabou, R.: Historia agraria en la España contemporánea. Cambio social y nuevas formas de propiedad, Barcelona, Crítica.

TORRAS I RIBÉ, Josep M. (1974): «La trajectoria d'un procés d'industrialització frustrat», Miscelania Aqualatensia, 2.

VIIAR, Pierre (1966): Catalunya dins de l'Espanya moderna. Recerques sobre els fonaments econòmics de les estructures nacionals, Barcelona, Ed. 62.

Zn moRA, Francisco (1973): Diario de los viajes bechos en Cataluña, Barcelona, Curial.

Zelinsky, Wilbur (1971): «The Hipothesis of the Mobility Transition», The Geographical Review, 61, 2. 